\title{
Analytical Model for Energy-Ecoefficiency based on Life Cycle Analysis
}

\author{
Johnny Nahui-Ortiz, Ph.D. ${ }^{1}$, Caroline Camarena-Gamarra ${ }^{1}$, Alejandro Mendoza ${ }^{1}$ \\ 1National University of Engineering, Peru, jnahuio@uni.edu.pe, ccamarenag@uni.pe, amen807@hotmail.com
}

\begin{abstract}
Ecoefficiency involves a number of possible strategies oriented to make a better use of resources in any organization. Potential improvements include products, processes, and services. There are different strategies oriented to enhance ecoefficiency levels at organizations by optimizing the use of resources. Energy, by all means, plays a key role for ecoefficiency at all levels. Traditional cost-benefit analysis is based on simple payback or equivalent.
\end{abstract}

Life Cycle Analysis makes an important contribution to a costbenefit analysis evaluation by incorporating aspects associated raw materials, production, distribution, end use, and disposal. Evaluation of potential savings attributed to ecoefficiency strategies may then be considered in a more sustainable framework incorporating aspects from an LCA perspective.

For illustration purposes, a small manufacturing plant located in Lima, Peru is considered as a reference case. A typical measure associated with the use of a more efficient lighting system would save around $20 \%$ of total cost with a return on investment of about 2 years. The amount of electricity saved would also have impacts within an LCA approach, considering for instance the nature of the national electricity grid. Also, the lamp to be purchased for the more efficient lighting systems would also have impacts within an LCA approach, taking into account for instance the fabrication site of the lamp.

By including an LCA approach into an energy-ecoefficiency management system, a more accurate payback calculation might be carried out.

Keywords-Energy, Ecoefficiency, Life Cycle Analysis, CostBenefit Evaluation, Environmental Management.

\section{INTRODUCTION}

A research group named Energy and Sustainable Development was formed at the Environmental Engineering Department in the National University of Engineering (FIAUNI) by a team of lecturers and students. A previous work from the aforementioned research group focused on developing a proper methodology in order to apply effectively cleaner production strategies. At present, the research group is interested in promoting strategies that may contribute to improve ecoefficiency levels in local organizations. There is a local perception that a more efficient use of resources involves high investment costs associated with long payback periods.

\section{A. Background on Energy-Ecoefficiency}

In Ref. [1], starting from sustainable development, energy efficiency and energy management fundamentals, a detailed analysis of the energy management systems standard ISO 50001:2011 was carried out from the viewpoint of sustainable

Digital Object Identifier (DOI):

http://dx.doi.org/10.18687/LACCEI2020.1.1.102

ISBN: 978-958-52071-4-1 ISSN: 2414-6390 development. The purpose of the analysis was to assess the effectiveness of its implementation, to identify the existence of gaps and to develop improvements capable of fulfilling the identified gaps. The effectiveness and the results of ISO 50001:2011 implementation, combined with the construction of an ideal energy management system allowed the identification of four gaps.

In Ref. [2], energy management has become crucial for the industrial sector as a structured approach to lowering the cost of production and in reducing the carbon footprint. With the development of ISO 50001 standard, energy management has enticed the attention of upper level management in terms of continuous improvement. The ISO 50001 standard requires an intensive energy assessment process to identify SEUs and EnPI, based on which target energy reductions can be realized.

In Ref. [3], non-renewable fuels are the world's main source of energy. However, the decrease in supply, increased demand, higher product costs and adverse effects on the environment led to the need to create the ISO 50001: 2011 standard to implement the Energy Management System (EnMS) in order to increase energy efficiency and reduce the emission of greenhouse gases (GHG).

In Ref. [4], energy consumption in the industrial and commercial (service) sectors accounts for nearly $40 \%$ of global greenhouse gas emissions. Reducing this energy consumption will be critical for countries to achieve their national greenhouse gas reduction commitments. The ISO 50001-Energy management standard provides a continual improvement framework for organizations to reduce their consumption. Several national policies already support ISO 50001; however, there is no transparent, consistent process to estimate the potential impacts of its implementation.

In Ref. [5], the research paper focuses on the assessment of the application of the International Standard ISO 50001 by municipalities in order to facilitate the implementation of their sustainable energy action plans. Traditional energy management schemes are combined with provisions of the standard by applying measurable energy indicators. Discussions address crucial issues like availability of energy data, lack of measurable indicators in action plans and challenges in the application of standard procedures in the municipality.

\section{B. Background on Life Cycle Analysis}

In Ref. [6], the article examines the concept of ecoefficiency at a regional level as an approach to promote the sustainable transformation of regions. The combined application of Life Cycle Assessment (LCA) and Data Envelopment Analysis (DEA) - the input-oriented BCC 
(Banker/Charnes/Cooper) model - has been chosen as a tool for the comprehensive ecoefficiency assessment, due to its high capability to measure regional ecoefficiency.

According to Ref. [7], sustainability concerns have increasingly gained importance among organizations and their stakeholders around the world. In this context, ecoefficiency has become a consistent tool towards the transition to sustainable development and the efforts of ecoefficiency indicators have been used for comparative studies and decision-making tasks, providing better financial, environmental, and social performance.

According to Ref. [8], life cycle assessment (LCA) is a commonly used tool to assess the amount of GHGs emitted over the life cycle of a service, policy or product system. The lack of data is a clear obstacle across methods. Further research is needed to develop comprehensive and robust modelling approach for ecosystem damages, which are not well covered in current Life Cycle Impact Assessment (LCIA) methods. Moreover, due to the scope of environmental LCA, there is a lack of consideration on socio-economic consequences, which may not be negligible for climate change.

In Ref. [9], it is stated that uncertainty in the results of input-output-based life cycle assessment models makes the sustainability performance assessment and ranking a challenging task. The major contribution of the proposed framework is that the effects of uncertainty associated with input-output-based life cycle assessment approaches can be successfully tackled with the proposed Fuzzy DEA framework which can have a great area of application in research and business organizations that use with ecoefficiency as a sustainability performance metric.

In Ref. [10], it is stated that Life Cycle Assessment (LCAs) of energy efficiency and environmental performance of buildings are deemed critical to address sustainable development issues. The methodological approach of the study leads to development of a whole building life cycle formula that sums up the contributions from a set of LCAs. By doing so, the paper highlights the necessity of LCA applications in buildings, the need for minimization of resource and energy consumption and environmental impact. The study helps in better understanding the way LCA supports the search for and identification of innovation pathways in buildings.

According to Ref. [11], LCA studies reveal emission hotspots along the whole product value chain allowing the researcher to identify opportunities for improvements. Its combination with integrative design offers an opportunity to substantially improve the ecoefficiency. Integrative approaches coupled with systematic, science-based assessment tools such as LCA can be effective in overcoming some of the barriers and improving ecoefficiency.

In Ref. [12], the life cycle assessment (LCA) modelling is used to assess the environmental impact, GHG emissions and the life cycle cost (LCC) are used as an extension of LCA in the term of economic dimension. Aligning both LCA and LCC in environmental-cost effectiveness as the ecoefficiency analysis helps in measuring sustainability.

In Ref. [13], it is stated that due to the diversity of different methods there has been, surprisingly, no detailed investigation of the different methods, the interrelationship between methods, and more importantly how they can advance integrated methods for Life Cycle Assessment (LCA) and Life Cycle Costing (LCC). The hybridized framework is the first of its kind and aims to provide decision-makers a comprehensive method to navigate environmental and economic analysis.

According to Ref. [14], a life-cycle model was implemented to a single-family house from the beginning of the 20th century retrofitted to be used as an office building. Different retrofit strategies should be adopted to maximize savings and minimize environmental impacts depending on the type of use and occupancy level. Therefore, it is crucial to take into account both the economic and environmental perspective to support a comprehensive retrofit decision process.

Last but not least, according to Ref. [15], the prominent conflict between today's rapidly growing building projects and the deteriorating natural environment demands proper assessment of the ecological efficiency of a project in its life cycle. Two comprehensive ecoefficiency indices based on lifecycle eco-footprint are developed: per capita annual efficiency and space efficiency, which are used to assess the efficiency of the eco-footprint consumed by the project throughout its life cycle and determine if the eco-footprint consumed in realizing the above mentioned functional values is ecologically sustainable.

\section{METHODOLOGY}

\section{A. Energy-Ecoefficiency Management}

According to Ref. [18], an energy management system helps organizations to better manage their energy use, thus improving productivity. It involves developing and implementing an energy policy, setting achievable targets for energy use, and designing action plans to reach them and measure progress. This might include implementing new energy-efficient technologies, reducing energy waste or improving current processes to cut energy costs.

ISO 50001 gives organizations a recognized framework for developing an effective energy management system. Like other ISO management system standards, it follows the "PlanDo-Check-Act" process for continual improvement.

ISO 50001 provides a set of requirements that enable organizations to:

- Develop a policy for more efficient use of energy

- Fix targets and objectives to meet that policy

- Gather data to better understand and make decisions concerning energy use

- Measure the results obtained

- Review the effectiveness of the policy

- Continually improve energy management 
ISO 50001 is designed to help your organization improve its energy performance through making better use of its energy-intensive assets. Improved energy performance can provide rapid benefits for an organization by maximizing its use of energy sources and energy-related assets, reducing both cost and consumption.

ISO 50001 is used by large and small organizations all over the world. Its benefits can take many forms. For some, it is about reducing the environmental impact and enhancing reputation; for others, the aim is to drive down costs and improve competitiveness.

Like all ISO management system standards, ISO 50001 has been designed for implementation by any organization in the public or private sector, whatever its size, activity or geographical location.

ISO 50001 does not fix targets for improving energy performance, which is left up to the user organization or regulatory authorities. This means that any organization, regardless of its current level of energy performance, can implement ISO 50001 to establish a baseline and improve on it at its own rate. The following figure shows a squeme proposed by ISO 50001 .

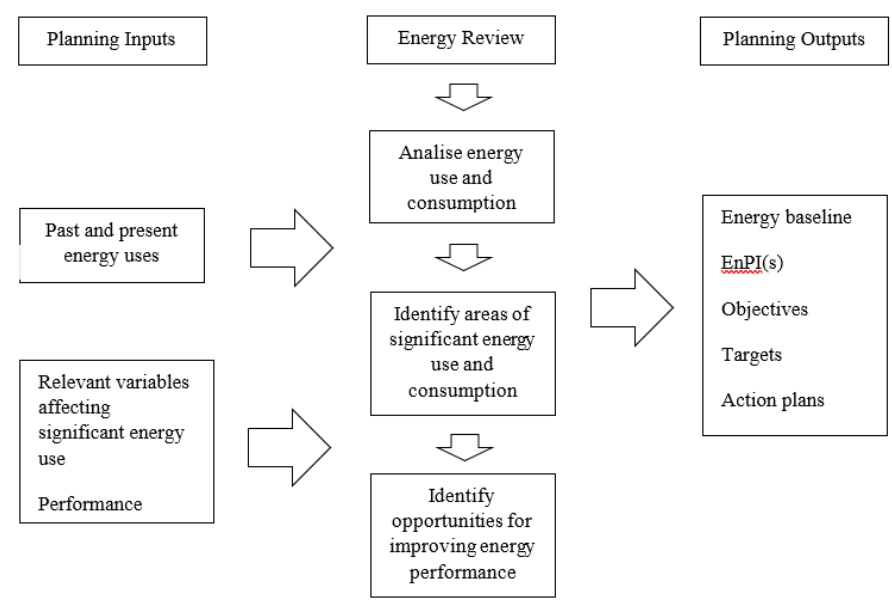

Fig. 1 Squeme for application of Energy-Ecoefficiency Management

\section{B. Life Cycle Analysis}

According to Ref. [16] and Ref. [17], the heightened awareness of the importance of environmental protection, and the possible impacts associated with products manufactured and consumed, has increased the interest in the development of methods to better comprehend and reduce these impacts. One of the techniques being developed for this purpose is Life Cycle Assessment (LCA). This International Standard describes the principles and framework for conducting and reporting LCA studies, and includes certain minimal requirements.

LCA is a technique for assessing the environmental aspects and potential impacts associated with a product, by

- compiling an inventory 2) of relevant inputs and outputs of a product system;
- evaluating the potential environmental impacts associated with those inputs and outputs;

- interpreting the results of the inventory analysis and impact assessment phases in relation to the objectives of the study.

LCA studies the environmental aspects and potential impacts throughout a product's life (i.e. cradler-to-grave) from raw material acquisition through production, use and disposal. The general categories of environmental impacts needing consideration include resource use, human health, and ecological consequences.

LCA can assist in

- identifying opportunities to improve the environmental aspects of products at various points in their life cycle;

- decision-making in industry, governmental or nongovernmental organizations (e.g. strategic planning, priority setting, product or process design or redesign);

- selection of relevant indicators of environmental performance, including measurement techniques; and

- marketing (e.g. an environmental claim, ecolabelling scheme or environmental product declaration).

This International Standard recognizes that LCA is still at an early stage of development. Some phases of the LCA technique, such as impact assessment, are still in relative infancy. Considerable work remains to be done and practical experience gained in order to further develop the level of LCA practice. Therefore, it is important that the results of LCA be interpreted and applied appropriately.

If LCA is to be successful in supporting environmental understanding of products, it is essential that LCA maintains its technical credibility while providing flexibility, practicality and cost effectiveness of application. This is particularly true if LCA is to be applied within small- and medium-sized enterprises.

The scope, boundaries and level of detail of an LCA study depend on the subject and intended use of the study. The depth and breadth of LCA studies may differ considerably depending on the goal of a particular LCA study. However, in all cases, the principles and framework established in this International Standard should be followed.

LCA is one of several environmental management techniques (e.g. risk assessment, environmental performance evaluation, environmental auditing, and environmental impact assessment) and may not be the most appropriate technique to use in all situations. LCA typically does not address the economic or social aspects of a product.

Because all techniques have limitations, it is important to understand those that are present in LCA. The limitations include the following.

- The nature of choices and assumptions made in LCA (e.g. system boundary setting, selection of data sources and impact categories) may be subjective.

- Models used for inventory analysis or to assess environmental impacts are limited by their assumptions, and may not be available for all potential impacts or applications. 
- Results of LCA studies focused on global and regional issues may not be appropriate for local applications, i.e. local conditions might not be adequately represented by regional or global conditions.

- The accuracy of LCA studies may be limited by accessibility or availability of relevant data, or by data quality, e.g. gaps, types of data, aggregation, average, site-specific.

- The lack of spatial and temporal dimensions in the inventory data used for impact assessment introduces uncertainty in impact results. This uncertainty varies with the spatial and temporal characteristics of each impact category.

Generally, the information developed in an LCA study should be used as part of a much more comprehensive decision process or used to understand the broad or general trade-offs. Comparing results of different LCA studies is only possible if the assumptions and context of each study are the same. These assumptions should also be explicitly stated for reasons of transparency.

This International Standard provides principles and framework and provides some methodological requirements for conducting LCA studies. Additional details regarding methods are provided in the complementary International Standards IS0 14041, IS0 14042 and IS0 14043 concerning the various phases of LCA.

The following figure shows a proposed squeme for an LCA approach.

\section{Organization Facility}

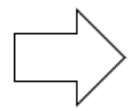

Product Life Cycle

RawMaterials

\begin{tabular}{|c|}
\hline Production \\
\hline Distribution \\
\hline \\
\hline End Use \\
\hline \\
\hline Disposal \\
\hline
\end{tabular}

Fig. 2 Squeme for application of a Life Cycle Analysis

\section{INTEGRATION OF ENERGY-ECOEFFICIENCY AND LIFE CYCLE ANALYSIS}

According to ISO 50001, main goals of an energy management systems are to obtain energy savings and, as a result of that, to achieve carbon emission reduction. Potential energy cost savings can be realized by carrying out best practices, replacing current equipment with more efficient units, and adopting innovative technology.

In order to determine whether a propose measure for improving ecoefficiency levels in an organization is feasible or not, an integrated evaluation must be considered. Such evaluation would involve technology assessment, economic aspects, and environmental impact. A technology assessment should validate a proposed replacement of an equipment or component in order to prevent negative impacts for processes or services, which the end user must keep carrying out. Also, a quantification of improved energy efficiency is needed based on technical specifications from suppliers or manufacturers. Economic aspects should be considered including energy costs, potential savings, implementation cost, and expected return on investment. Environmental impact should consider GHG emission reductions, particularly carbon dioxide, and other relevant aspects associated with local environmental regulations.

According to LCA, main aspects to be considered are raw materials, production, distribution, end use, and disposal. Best practices usually do not involve purchase of equipment or components. It basically deals with improving control or operation of the system as it is. Expected outcomes would be shown as a reduction of the energy source that is presently used. Replacement of current equipment or component with a more efficient unit would involve purchasing new items. It should be noted, for example, that in several developing countries, most of the equipment or components, particularly for industrial and commercial purposes, come from overseas since they are not manufactured locally. Adoption of innovative technology would also be related to the use of imported, sophisticated, and advance energy systems.

Therefore, it is expected that the incorporation of an LCA approach into an energy-ecoefficiency management system would contribute to reflect, in a more accurate fashion, the cost-benefit of a proposed measure for improving the ecoefficiency level in an organization. The following figure shows a proposed model wherein life cycle analysis might be included in the energy-ecoefficiency evaluation.
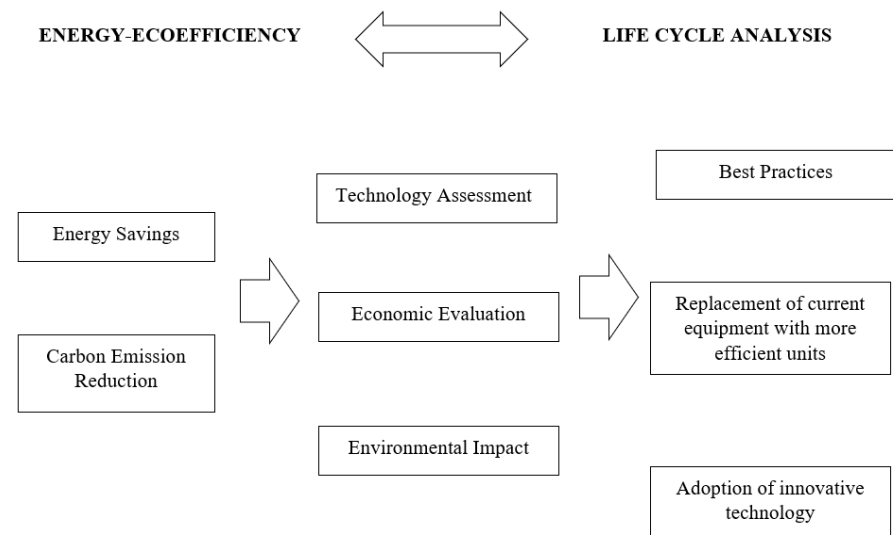

Fig. 3. Proposed model for energy-ecoefficiency integration with life cycle analysis 


\section{APPLICATION OF PROPOSED MODEL}

For illustration purposes, a very common case of an energy efficiency measure will be considered for application of the proposed model. Energy consumption for lighting is a fairly common issue in organizations, including industrial and commercial facilities. By promoting a more efficient use of electricity, it is expected that the ecoefficiency level of the organization will be improved.

Local energy audits indicate that in a typical small manufacturing plant, located in Lima, Peru, around $20 \%$ of total energy cost belongs to lighting usage. The same energy audits also indicate that up to $15 \%$ of total energy cost savings can be achieved by implementing energy efficiency measures. Local electricity cost can be estimated as $0.12 \mathrm{US} \$ / \mathrm{kWh}$ for small manufacturing plants. According to past experiences, local implementation costs usually leads to a simple payback of around 2 years.

Now, if Life Cost Analysis is incorporated, as proposed, additional aspects would also intervene in the above classical payback calculation.

Let us take for instance the components of the national electric grid and the efficient lighting lamp.

First, the national electric grid is composed by distinct electric utilities. According to figures from the last year, electricity is generated from hydropower plants $(46 \%)$, thermal power plants $(50 \%)$ and solar-wind power plants $(4 \%)$

Carbon dioxide emissions per unit of electricity generated by the national electric grid is currently estimated as 0.7 $\mathrm{tCO}_{2} / \mathrm{MWh}$. Local thermal power plants run mostly on natural gas, but also some units run on coal, fuel oil, and diesel oil. The components of thermal power plants, including gas and steam turbines, as well as boilers, condensers, air compressors, water pumps, and others, are all mostly built elsewhere. Therefore, within LCA approach, aspects associated with raw materials or production may not need to be considered. However, aspects related to distribution (shipping from overseas to the country), end use (within expected life for power plant operation) and disposal should be considered. On the other hand, fuels consumed by power plants come from within the country. A major cluster of thermal power plants is located south of the city of Lima, and receives natural gas that comes from $700 \mathrm{~km}$ far away. Therefore, within LCA approach, raw materials and production phases associated with extraction and processing of natural gas should be considered. A 32-inch pipeline transports the natural gas from extraction point to thermal power plant location. Electricity generated on site is then delivered through electric transmission lines and distribution grids to the small manufacturing plant. Aspects related to end use and disposal of electricity may not need to be considered in this case.

Second, the efficient lighting lamps that would be purchased to replace the existent lighting lamps are not manufactured locally. Lighting bulbs are currently being manufactured overseas, mainly in the Asian region. Therefore, within LCA approach, raw materials and production aspects may not need to be considered. However, aspects related to distribution (shipping from overseas to the country), end use, and disposal, should be considered. For instance, compact fluorescent lamps have an expected life of about 5,000 hours; however, LED lamps have an expected life of about 30,000 hours.

The following figure shows an insight of a possible application of the proposed model for a reference case associated with improving energy efficiency in lighting for a small local manufacturing plant.

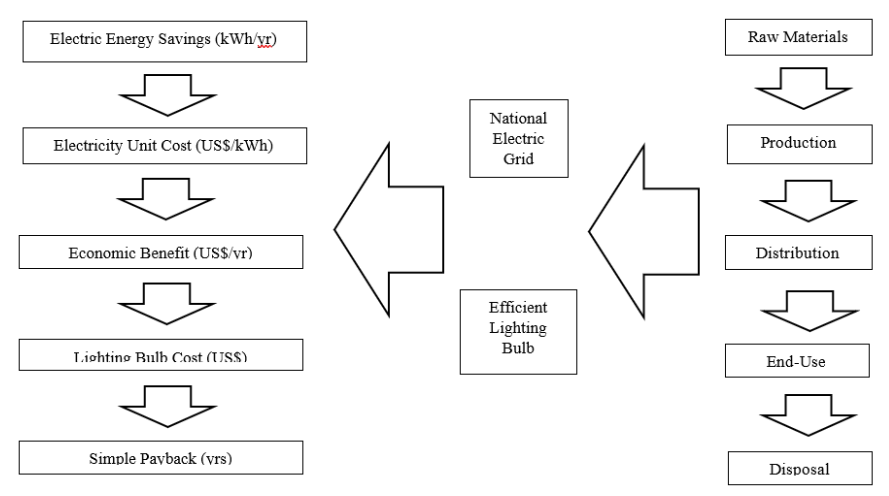

Fig. 4. Sample application of proposed model

It is anticipated that the previous payback calculation would become more attractive after the incorporation of additional benefits coming from saving energy and using a more efficient lighting within an LCA approach.

\section{CONCLUSIONS}

Ecoefficiency involves different opportunities for improvement and operating cost reduction in all organizations. Energy comes up as a major resource that needs particular attention due to its impact both in economic and environmental aspects.

An energy management system such ISO 50001, focuses on both energy savings and carbon emission reduction while an LCA approach includes raw materials, production, distribution, end use, and disposal.

Energy-Ecoefficiency measures include best practices, replace old equipment with more efficient units, and adoption of innovative technology. Cost-benefit of implementing such measures will depend on the nature of the measures. Also, LCA aspects to be incorporated will also depend on the nature of the measures.

Traditional payback evaluation is based on expected cost savings (as a function of expected energy savings) and implementation cost (in order to achieve the expected energy savings).

By including an LCA approach into an energyecoefficiency management system, a more accurate payback calculation might be carried out. 


\section{ACKNOWLEDGMENT}

The authors would like to thank the staff members and authorities of the Environmental Engineering Department at the National University of Engineering, in Lima-Peru, for sharing their time and experience with the research team in order to facilitate data collection. The authors would also like to thank to all the people that, in one way or another, contributed to the present work.

\section{REFERENCES}

[1] DA SILVA Vitor, DOS SANTOS Feliz. Energy management system ISO 50001:2011 and energy management for sustainable development. Instituto Superior de Engenharia de Lisboa. Lisboa, Portugal. 2019.

[2] KANNEGANTI Harish, GOPALAKRISHNAN Bhaskaran, CROWE Ed, AL-SHEBEEB Omar, ABOLHASSANI Amir. Specification of energy assessment methodologies to satisfy ISO 50001 energy management standard. West Virginia University, Morgantown, WV, USA. 2017.

[3] LIRA Jean, SALGADO Eduardo, BEIJO Luiz. Which factors does the diffusion of ISO 50001 in different regions of the world is influenced? Federal University of Alfenas. Minas Gerais, Brazil. 2019.

[4] MCKANE Aimee, THERKELSEN Peter, SCODEL Anna, RAO Prakash, O'SULLIVAN John. Predicting the quantifiable impacts of ISO 50001 on climate change mitigation. Lawrence Berkeley National Laboratory, California, USA. 2017.

[5] DZENE Ilze, POLIKARPOVA Ilze, ZOGLA Liga, ROSA Marika. Application of ISO 50001 for Implementation of Sustainable Energy Action Plans. Riga Technical University, Institute of Energy Systems and Environment, Riga, Latvia. 2015.

[6] RYBACZEWSKA-BLAZEJOWSKA Magdalena, MASTERNAKJANUS Aneta. Eco-efficiency assessment of Polish regions: joint application of life cycle assessment and data envelopment analysis. Kielce University of Technology. Poland. 2018.

[7] CAIADO, R. Towards sustainable development through the perspective of ecoefficiency - A systematic literature review. Fluminense Federal University. Brazil. 2017.

[8] DONG Yan, HAUSCHILD Michael, SORUP Hjalte, ROUSSELET Remi, FANTKE Peter. Evaluating the monetary values of greenhouse gases emissions in Life Cycle Impact Assessment. University of Denmark. Denmark. 2019.

[9] EGILMEZ Gokhan, GUMUS Serkan, KUCUKVAR Murat, TATARI Omer. Fuzzy Data Envelopment Analysis Framework for Dealing with Uncertainty Impacts of Input-Output Life Cycle Assessment Models on Eco-efficiency Assessment. University of New Haven, West Haven, CT USA. 2016.

[10] INGRAO Carlo, MESSINEO Antonio, BELTRAMO Riccardo, YIGITCANLAR Tan, LOPPOLO Giuseppe. How can life cycle thinking support sustainability of buildings? Investigating life cycle assessment applications for energy efficiency and environmental performance. Italy. 2018.

[11] KULAK Michal, NEMECEK Thomas, FROSSARD Emmanuel, GAILLARD Gerard. Eco-efficiency improvement by using integrative design and life cycle assessment. The case study of alternative bread supply chains in France. Institute for Sustainability Sciences. Switzerland. 2016

[12] MAH Chooi, FUJIWARA Takeshi, HO Chin. Life cycle assessment and life cycle costing toward ecoefficiency concrete waste management in Malaysia. Universiti Teknologi Malaysia. Malaysia. 2018.

[13] MIAH J.H., KOH S.C.L., STONE D. Hybridised framework combining integrated methods for environmental life cycle assessment and life cycle costing. Sheffield University Management School. United Kingdom. 2017.

[14] RODRIGUES Carla, FREIRE Fausto. Adaptive reuse of buildings: ecoefficiency assessment of retrofit strategies for alternative uses of an historic building. University of Coimbra. Portugal. 2017.
[15] TENG Jiaying, WU Xianguo. Eco-footprint-based life-cycle ecoefficiency assessment of building projects. Huazhong University of Science and Technology. China. 2014.

[16] INTERNATIONAL STANDARD ORGANIZATION. ISO 14040. Environmental management - Life cycle assessment - Principles and framework. 2006.

[17] INTERNATIONAL STANDARD ORGANIZATION. ISO 14044. Environmental management - Life cycle assessment - Requirements and Guidelines. 2006.

[18] INTERNATIONAL STANDARD ORGANIZATION. ISO 50001. Energy Management Systems. Requirements and Guidelines for Use. 2018. 